\title{
Large Pantaloon Hernia in a Five-months-old Infant
}

\section{Soumyodhriti Ghosh ${ }^{1} \cdot$ Kumar Mitrabhanu $^{2}$ (D) $\cdot$ Smriti Nath $^{2} \cdot$ Rajiv Sharan $^{2} \cdot$ Mananjay Prasad $^{1}$}

Received: 23 April 2020 / Accepted: 5 May 2020 / Published online: 16 May 2020

(C) Dr. K C Chaudhuri Foundation 2020

To the Editor: Inguinal hernia occurs more commonly in premature infants than in the general population with incidence being up to $30 \%$. They are almost always indirect type [1,2]. Direct inguinal hernia is rare in infants. We describe an extremely rare case of ipsilateral, concurrent direct and indirect hernias in an infant, also known as a pantaloon or dual hernia.

A five-months-old male infant attended with huge unilateral (right) scrotal swelling since birth. He had a history of prematurity, born at $30 \mathrm{wk}$ gestation and Neonatal intensive care unit (NICU) stay after birth. There was a large, right inguinal hernia that was reduced back with difficulty. The patient was taken up for surgery. Following inguinal exploration, the indirect hernia sac was divided and high ligated. On careful evaluation, surprisingly, the deep ring was inappropriately wide and a gap could be identified in the floor of the inguinal canal through which herniating bowel contents could be seen (Direct component). The fascia transversalis was repaired with non-absorbable sutures to strengthen the floor of the inguinal canal. Postoperative period was uneventful.

Risk factors for inguinal hernias in infancy include prematurity, urogenital anomalies, connective tissue disorders like Ehlers-Danlos syndrome, Marfan syndrome, mucopolysaccharidosis, abdominal wall defects and Cystic fibrosis [2-4]. In our patient, prematurity appeared to be the only predisposing factor. Direct inguinal hernia in children may be of three types- a) primary wall weakness without notable indirect component; b)

Kumar Mitrabhanu

dr.mitrabhanu@gmail.com

Pediatric Surgery Unit, Abhishek Child And Maternity Centre, Jamshedpur, India

2 Department of Pediatrics, Tata Motors Hospital, Telco, Jamshedpur 831003, India direct sliding hernia; c) very large indirect sac causing rupture of the inguinal floor causing direct defect [2]. In our patient, it appears that the large indirect sac with heavy contents caused widening of the deep ring and weakened the fascia transversalis causing the floor of the canal to give way and resulted in the direct hernia. Therefore, in all babies with large hernia presentations and/or with predisposing factors, it is important to carefully visualize the floor of the inguinal canal to avoid missing a concurrent direct hernia. If present, repair of the inguinal floor must be done to reduce the risk of recurrence in later life $[1-3,5]$.

\section{Compliance with Ethical Standards}

Consent Written informed consent was taken from the family for publication of clinical details and photographs of the patients.

Conflict of Interest None.

\section{References}

1. Helal AA. Inguinal hernia in infancy and children. Hernia. 2017;8: 59. https://doi.org/10.5772/intechopen.69378.

2. Inguinal hernias and hydroceles in infancy and childhood: A consensus statement of the Canadian Association of Paediatric Surgeons. Paediatr Child Health. 2000;5:461-2.

3. Wright JE, Gill AW. Direct inguinal hernias in the newborn. Aust N Z J Surg. 1991;61:78-81.

4. Schier F, Klizaite J. Rare inguinal hernia forms in children. Pediatric Surg Int. 2004;20:748-52.

5. Lau ST, Lee YH, Caty MG. Current management of hernias and hydroceles. Semin Pediatr Surg. 2007;16:50-7.

Publisher's Note Springer Nature remains neutral with regard to jurisdictional claims in published maps and institutional affiliations. 